\title{
Study on type-testing of a manual TLD-reader for dosimetry programs
}

\author{
S. M. Hosseini Pooya*, P. Rezaeian, E. Edalatkhah
}

Radiation Applications Research School, Nuclear Science \& Technology Research Institute, Tehran, Iran

\begin{abstract}
In a radiation individual monitoring program, the type testing of measuring devices is a great important part of the quality management system. The IEC-62387 standard applies to dosimetry systems that measure external photon and/or beta radiation within limited ranges of the associated physical parameters. In this work, a type-testing program was conducted for a manual thermoluminescence dosimetry (TLD) reader employing the IEC-62387 radiation and environmental performance criteria. The uncertainty of non-linearity of the response of the dosimetry system in a range of $0.7-850 \mathrm{mSv}$ was obtained between $-15 \%$ and $+17 \%$, which fulfilled the IEC standard range of $-16 \%$ to $+18 \%$. Furthermore, the total uncertainty of all reader tests was measured to be $12 \%$, which was less than the criteria of $20 \%$ in the IEC standard. Thus, it can be concluded that the TLD reader met all requirements of the IEC standard for the reader-tests by an appropriate margin.
\end{abstract}

Keywords: TLD reader, IEC, Type Test, Radiation, Standard

\section{INTRODUCTION}

Certain levels of radiological protection of workers are essential for the safe and justified use of ionizing radiation in wide ranges of applications in industries, medical, educational, and research institutions, agriculture, and nuclear facilities. Among the various passive monitoring techniques, thermoluminescent dosimetry (TLD) is the most common method used by service providers in the world due to its advantages. According to the International Atomic Energy Agency (IAEA) requirements, dosimetry systems should preferably be type-tested in accordance with the relevant standards, including International Electrotechnical Commission (IEC), the International Organization for Standardization (ISO) and/or equivalent national standards. They should meet the requirements passing the relevant tests [1].

The IEC 61066 [2] standard and its substituted version of IEC 82387 [3] have already been employed for the aim of type-testing on various models of TLD readers [4-9].

The criterion for meeting the requirements in these standards is to obtain the calculated values of each defined quantitative parameter within a certain range specified in the standard. In all the above investigations, the requirements of the used standard have been fulfilled for the conducted tests on various models of the TLD readers in the test programs. However, it should be noted that these standards are not applicable as a tool for the quality 
of all of a manufacturer's products or to compare various commercial models of TLD readers.

The IEC 62387 could be applied to all types of passive and active dosimetry systems used to measure the different operational quantities of personal dose equivalents, $H_{p}(d)$, and the ambient dose equivalent, $H^{*}(d)$. This IEC specifies general characteristics, test procedures and performance requirements, radiation characteristics, and environmental, electrical, mechanical, and software characteristics. Consequently, the test procedures are included comprehensive performance criteria of radiation and environmental.

Utilizing the IEC 62387 criteria, in this work, we conducted a reader-testing procedure for a new home-made manual TLD reader employed as one of the measuring instruments in any radiation monitoring services. Moreover, certain important criteria of the dosimetry system, which may include the significant contribution to a reader's performance, were assessed to ensure the quality of the reader.

\section{MATERIAL AND METHODS}

A manual model of 7103-Plus TLD reader (RSD Co.) has been already designed and manufactured in Iran and was used for the tests (Fig. 1). The reader consists of one photomultiplier tubes that can measure the emitted visible light from TLD chips, pellets, or powder during the linear heating of these materials. The TL glow-curve could be calculated and drawn with a comprehensive software program and indicated on a PC monitor connected to the device.

Over 100 pre-calibrated LiF:Mg,Ti TLD chips (TLD-100, Harshaw) were used in this quality test program. The dosemeters were irradiated to the photons of a ${ }^{60} \mathrm{Co}$ reference source, which their dose fields were traceable to the national secondary standard dosimetry laboratory. The dosimetry system tests, including; non-linear response, overload, after effects and reusability, and the environmental tests including; light exposure, ambient temperature, reader stability and power supply, were investigated in this type-testing program. Except the ambient temperature, all tests were carried out on the reference condition of $23^{\circ} \mathrm{C}$ temperature in our laboratory. The laboratory temperature ranged from 15 to $40^{\circ} \mathrm{C}$ in the ambient temperature test.

Moreover, all tests, except the light exposure, were conducted under the normal light intensity of the laboratory ( 150 lux). The effect of light exposure was investigated. Thus the reader was directly exposed to the light of 1000 lux. The dose equivalent quantity of $\mathrm{Hp}(0.07)$ was used in all measurements. According to the IEC 62387 standard, the following procedures were utilized.

\section{A. Non-linearity of response}

Since the linearity of response is an essential parameter for any dosimetry system, the nonlinearity response of the reader was studied as the first test. The dosemeters were irradiated to ${ }^{60} \mathrm{Co}$ reference source to the twelve dose values of 0.7 up to $850 \mathrm{mSv}(w=12)$ in which four repeated measurements $(n=4)$ were performed at those values. Accordingly, the corresponding value of $c_{1}$ and $c_{2}$ (two tabulated numerical parameters defined in the standard) were derived 1.269 and 1.840, respectively, from Table 2 of IEC standard $[3,10]$. The mean indicated value $G_{i}$ and the standard deviation $s_{i}$ were determined for each dose $C_{i}$. 
Another requirement was that the inequality 0.91

$-U_{C, \text { com }} \leq\left(\left(G_{i} /_{G r, 0}\right) \pm U_{c o m}\right) \cdot\left(C_{r, 0} / C_{r}\right) \leq 1.11+$ $U_{C \text {,com }}$ should be valid, where $C_{r}$ is the conventional true value of (delivered) dose equivalent under reference conditions, $C_{r, 0}$ is as $C_{r}$ but only for reference dose equivalent, $U_{c o m}$ is the expanded uncertainty of a combined quantity and $U_{C \text {,com }}$ is the expanded uncertainty of a combined quantity of conventional true values.

\section{B. Overload, after effect and reusability}

Four groups of dosemeters were exposed to the ${ }^{60} \mathrm{Co}$ source to the following high- and low-dose values, respectively.

Group 1: Reference group: five dosemeters were irradiated with $C_{r, 0}=10 \mathrm{mSv}$.

Group 2: One dosemeter was irradiated with a high dose equivalent of $1 \mathrm{~Sv}$.

Group 3: Ten dosemeters were irradiated with a dose equivalent of $0.7 \mathrm{mSv}\left(H_{\text {low }}\right)$.

Group 4: Ten dosemeters were irradiated with a dose of $10 \mathrm{mSv}$. Then, the usual method of preparing the dosemeters was applied for a new irradiation. Finally, the dosemeters were irradiated with a dose equivalent of $0.3 \mathrm{mSv}$. For every dose value, the mean indicated value $G_{i}$ and the standard deviation $s_{i}$ were determined [3].

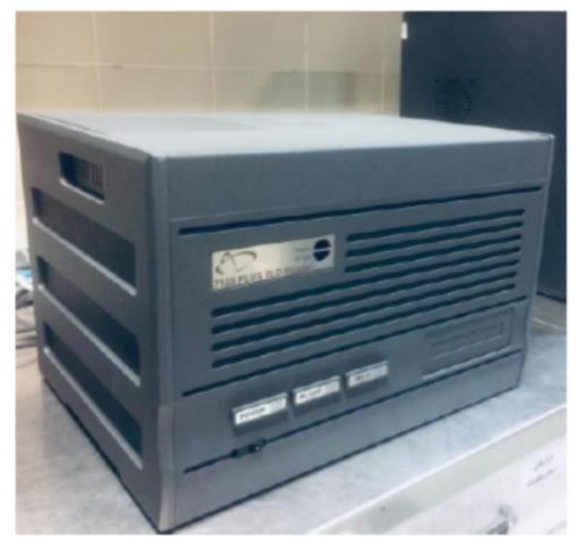

Fig. 1. A manual TLD Reader model of 7103-Plus C. Light exposure
Two groups of seven dosemeters were exposed to the ${ }^{137} \mathrm{Cs}$ source.

Group 1: Reference group: the reader was exposed to additional light than the usual daylight in shadow, and the dosemeters were read out.

Group 2: The parts of the reader near the seal of the photomultiplier were exposed to a high-density light source (1000 lux) and the dosemeters were read out.

Groups 1 and 2 were exposed to $4.9 \mathrm{mSv}\left(7 H_{\text {low }}\right)$. The mean indicated value $G_{i}$ and the standard deviation $s_{i}$ were determined for every group. The influence quantity was assumed to be type $\mathrm{S}$ (influence quantity whose effect on the indicated value is a deviation independent of the indicated value) [3].

\section{Ambient temperature}

This test was done in a $15-40^{\circ} \mathrm{C}$ temperature range. Two groups of seven dosemeters were exposed to the ${ }^{137} \mathrm{Cs}$ source for this test.

Groups 1 and 2 were exposed to $4.9 \mathrm{mSv}$. The laboratory temperature was fixed by a vapor compression refrigeration system (cooling-heating system).

Group 1: Reference group: the ambient temperature was at standard test conditions and the dosemeters were read out.

Groups 2: The reader's temperature was held $4 \mathrm{~h}$ at $40^{\circ} \mathrm{C}$ temperature. At the end of $4 \mathrm{~h}$, the read-out of the dosemeters was performed by holding the temperature.

The mean indicated value $G_{i}$ and the standard deviation $s_{i}$ were determined for every group. The influence quantity was assumed to be type F [3]. 


\section{E. Reader stability}

Three groups of seven dosemeters were used in this test.

Group 1 was irradiated at the beginning of the typetest and read out 1 week later.

Group 2 was irradiated to the same dose as group 1 , after 1 month, and read out 1 week later.

Group 3 were irradiated to the same dose as groups 1 and 2, after 2 months, and read out 1 week later. The mean indicated value $G_{i}$ and the standard deviation $s_{i}$ were determined for every group. The influence quantity was assumed to be of type F [3].

\section{F. Primary power supply}

The reader has been so electrically designed that any fluctuations in frequency and voltage never affect the TLD read-outs. However, the following procedure was conducted to ensure that the IEC standard criteria were met. Two groups of dosemeters were exposed to the ${ }^{137} \mathrm{Cs}$ source in this test.

Group 1: Reference group: seven dosemeters were read out under a stable nominal power supply voltage and frequency $(220 \mathrm{~V}, 50 \mathrm{~Hz})$, achieved by an uninterruptable power supply system.

Group 2: Twenty dosemeters were read out under random and simultaneous changes of frequency and voltage from 40.7 to $50.3 \mathrm{~Hz}$ and from 190 to $240 \mathrm{~V}$, respectively, at the peak energy consumption times.

The mean indicated value $G_{i}$ and the standard deviation $s_{i}$ were determined for every group. The influence quantity was assumed to be of type F.

\section{RESULTS AND DISCUSSION}

\section{A. Dosimetry system performance test results}

Table 1 exhibits the full results obtained for the non-linearity of response. According to the IEC 62387 standard (line 6 of Table 8), the coefficient of variations (COVs) must fulfill the requirements presented as: for the doses of $\mathrm{H}<0.1,0.1 \leq \mathrm{H}<$ 1.1 , and $H \geq 1.1 \mathrm{mSv}$, the COVs must be less than $15 \%,(16-H / 0.1 \mathrm{mSv}) \%$ and $5 \%$, respectively.

The values of COV (which is defined as the ratio of $s_{\mathrm{i}} / G_{\mathrm{i}}$ ) were obtained less than those of the criteria in Table 8 of the IEC standard (i.e. the product of the given values in line 6 of the table by $c_{1}=1.269$ or $c_{2}=1.840$ ) to all the twelve dose values. Moreover, the calculated values of inequality $0.91-U_{C, \mathrm{com}} \leq\left(\left(G_{i} / G_{r, 0}\right) \pm U_{\mathrm{com}}\right) \cdot\left(C_{r, 0} / C_{r}\right)$ $\leq 1.11+U_{C \text {,com }}$ were valid to all the eight dose values. Thus, the requirements of non-linearity of response met the IEC criteria for the non-linearity of response.

An overload message was displayed on the system when the dosemeter of the second group was read out over $1500 \mathrm{nC}$. Afterward, the reading procedure was automatically stopped. In addition, the reader could continue the read-outs of dosemeters of group 3 on its usual way. After that the overload message stopped the reader. The inequality $0.91-U_{C, \text { com }} \leq\left(\left(G_{i} / G_{r, 0}\right) \pm U_{\text {com }}\right) \cdot\left(C_{r, 0} / C_{r}\right)$ $\leq 1.11+U_{C \text {,com }}$ was valid for the three other groups of dosemeters (Table 2). In addition, the COV of all groups was obtained less than those of the IEC standard criteria. Consequently, the requirements of IEC are considered to be met in overload, after effect, and reusability tests. 
Table 1

The non-linearity of response test results of IEC 62387 for TLD reader model of 7103-Plus

\begin{tabular}{|c|c|c|c|c|c|}
\hline $\begin{array}{l}\text { Dose } \\
\text { Value } \\
(\mathbf{m S v})\end{array}$ & $U_{\text {com }}$ & $U_{C, \text { com }}$ & $\begin{aligned} & \text { Test result for } \\
& 0.91-U_{C, \text { com }} \leq\left(\frac{\overline{G_{\boldsymbol{t}}}}{G_{r, 0}} \pm U_{c o m}\right) \cdot \frac{C_{r, 0}}{C_{r}} \\
& \leq \mathbf{1 . 1 1}+U_{C, c o m}\end{aligned}$ & $\begin{array}{c}\text { IEC Criteria for } \\
\operatorname{COV} \frac{s_{i}}{G}(\%)\end{array}$ & $\begin{array}{c}\text { Test result for } \\
\frac{s_{i}}{G}(\%)\end{array}$ \\
\hline 0.7 & 0.002 & 0.07 & $0.84 \leq 0.85 \_0.91 \leq 1.18$ & 15.0 & 1.93 \\
\hline 3 & 0.038 & 0.07 & $0.84 \leq 1.07 \_1.16 \leq 1.18$ & 13.0 & 2.95 \\
\hline 20 & 0.049 & 0.07 & $0.84 \leq 1.00 \_1.05 \leq 1.18$ & 5.3 & 0.71 \\
\hline 30 & 0.084 & 0.07 & $0.84 \leq 0.96 \_1.01 \leq 1.18$ & 5.3 & 1.22 \\
\hline 50 & 0.301 & 0.07 & $0.84 \leq 0.88 \_1.00 \leq 1.18$ & 5.3 & 3.79 \\
\hline 100 & 0.439 & 0.07 & $0.84 \leq 0.97 \_1.06 \leq 1.18$ & 5.3 & 4.08 \\
\hline 250 & 1.265 & 0.07 & $0.84 \leq 0.96 \_1.06 \leq 1.18$ & 5.3 & 2.86 \\
\hline 350 & 2.306 & 0.07 & $0.84 \leq 0.93 \_1.06 \leq 1.18$ & 5.3 & 3.95 \\
\hline 450 & 2.642 & 0.07 & $0.84 \leq 0.93 \_1.04 \leq 1.18$ & 5.3 & 3.51 \\
\hline 700 & 5.063 & 0.07 & $0.84 \leq 0.93 \_1.08 \leq 1.18$ & 5.3 & 4.33 \\
\hline 800 & 4.643 & 0.07 & $0.84 \leq 1.07 \_1.18 \leq 1.18$ & 5.3 & 2.91 \\
\hline 850 & 4.445 & 0.07 & $0.84 \leq 1.07 \_1.17 \leq 1.18$ & 5.3 & 2.56 \\
\hline
\end{tabular}

Table 3

The reader tests results of IEC 62387 for TLD reader model of 7103-Plus

\begin{tabular}{|c|c|c|c|c|c|c|c|}
\hline Test & Group no & $U_{\text {com }}$ & $r_{\min }$ & $r_{\max }$ & $\begin{array}{l}\text { Test result for } \\
\left(\frac{\overline{G_{l}}}{\overline{G_{m}}} \pm U_{\text {com }}\right)\end{array}$ & $\begin{array}{c}\text { IEC Criteria } \\
\text { for COV } \\
\frac{s_{i}}{G}(\%)\end{array}$ & $\begin{array}{c}\text { Test } \\
\text { result } \\
\text { for } \\
\frac{s_{i}}{G}(\%)\end{array}$ \\
\hline \multirow{3}{*}{ Stability } & 1 & \multicolumn{4}{|c|}{ Not Applicable (Reference Group) } & 6,0 & 3.5 \\
\hline & 2 & 0.04 & 0.91 & 1.11 & $0.92-0.99$ & 6.0 & 4,0 \\
\hline & 3 & 0.04 & 0.91 & 1.11 & $0.91-0.98$ & 6.0 & 4.0 \\
\hline \multirow{2}{*}{$\begin{array}{c}\text { Ambient } \\
\text { Temperature }\end{array}$} & 1 & \multicolumn{4}{|c|}{ Not Applicable (Reference Group) } & 11.0 & 4.4 \\
\hline & 2 & 0.01 & 0.91 & 1.11 & $0.92-0.96$ & 11.0 & 2.7 \\
\hline \multirow{2}{*}{ Light Exposure } & 1 & \multicolumn{4}{|c|}{ Not Applicable (Reference Group) } & 11.0 & 3.8 \\
\hline & 2 & 0.02 & 0.91 & 1.11 & $1.00-1.01$ & 11.0 & 2.0 \\
\hline \multirow{2}{*}{ Power Supply } & 1 & \multicolumn{4}{|c|}{ Not Applicable (Reference Group) } & 6.0 & 5.0 \\
\hline & 2 & 0.02 & 0.91 & 1.11 & $1.07-1.10$ & 6.0 & 2.0 \\
\hline
\end{tabular}


Table 2

The reusability and after-effect tests results of IEC 62387 for TLD reader model of $7103+$

\begin{tabular}{|c|c|c|c|c|c|c|}
\hline $\begin{array}{c}\text { Group } \\
\text { N0. }\end{array}$ & $\begin{array}{l}\text { Dose } \\
\text { Value } \\
(\mathrm{mSv})\end{array}$ & $U_{\text {com }}$ & $U_{\mathbf{C}, \mathbf{c o m}}$ & $\begin{array}{c}\text { Test result for } \\
0.91-U_{\mathrm{C}, \mathrm{com}} \leq\left(\frac{\overline{G_{\boldsymbol{\imath}}}}{\underline{G}_{r, 0}} \pm U_{\text {com }}\right) \cdot \frac{C_{r, 0}}{C_{r}} \\
\leq 1.11+U_{\mathrm{C}, \mathrm{com}}\end{array}$ & $\begin{array}{c}\text { IEC } \\
\text { criteria } \\
\text { for COV } \\
\frac{s_{i}}{G}(\%)\end{array}$ & $\begin{array}{l}\text { Test } \\
\text { result } \\
\text { for } \\
\frac{s_{i}}{G}(\%)\end{array}$ \\
\hline 1 & 10 & & & Not Applicable (Reference Group) & & \\
\hline 2 & 0.70 & 0.006 & 0.07 & $0.84 \leq 0.96-1.13 \leq 1.18$ & 13 & 10.31 \\
\hline 3 & 10 & 0.029 & 0.07 & $0.84 \leq 0.92 \_0.98 \leq 1.18$ & 5.29 & 4.385 \\
\hline 3 & 0.70 & 0.001 & 0.07 & $0.84 \leq 0.97 \_1.00 \leq 1.18$ & 5.29 & 1.613 \\
\hline
\end{tabular}

\section{B. Reader performance test results}

Table 3 presents the full results obtained from the environmental tests. In the light exposure test, since the value of inequality $\left|G_{2}-G_{1} \pm U_{\text {com }}\right| \leq D_{\max }$ was valid, the TLD reader met the IEC standard criteria in the test. In the ambient temperature, power supply, and stability tests, since the values of inequality $r_{\min } \leq\left(\left(G_{2} / G_{1}\right) \pm U_{\text {com }}\right) \leq r_{\max }$ are valid; the requirements of IEC standard were considered to be met for all three tests. Finally, considering the $r_{q}$ values defined for the influence quantities of type $\mathrm{F}$, the total uncertainty of all reader tests was measured to be $12 \%$, which was less than the criteria of $20 \%$ in standard mode. The calculated $r_{q}$ values showed in Table 4.

\section{Table 4.}

Total uncertainty of TLD reader model of 7103-Plus against the influence quantities of type $\mathrm{F}$ for reader tests

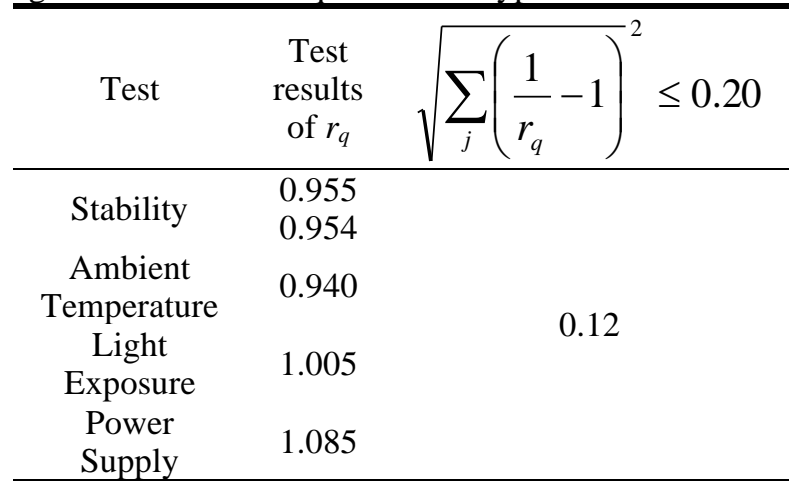

\section{Comparison with the other TLD readers}

In Table 5, the passed tests of model 7103-plus were summarized along with those of other various models of TLD readers already studied by other investigators. Since in the past investigations, either the IEC 61066 criteria have been used (Lue et. al, 2008; Velbeck et. al, 2006), or the IEC 62387 criteria have been employed incompletely (Rizk and Vanhavere, 2016), it is not possible to compare the various models of TLD-readers in this regards. However, considering the similarity in criteria of IEC 61066 and 62387 in the majority of tests, it can be concluded that the manual TLD reader model of 7103-Plus could be used at least with the same degree of performance of other commercial TLD readers in dosimetry laboratories.

\section{CONCLUSION}

The model 7103-Plus manual TLD reader met the criteria of IEC 62387 by large margins. Since the qualitative characteristics of TLD readers do not depend on the type of quantities, the obtained results for $\mathrm{Hp}(0.07)$ can be extended to measure the other dose quantities of $\mathrm{Hp}(10), \mathrm{Hp}(3)$, and $\mathrm{H}^{*}(10)$ with the same degree of uncertainties. The equipped reader with the comprehensive software can be used reliably and efficiently in an accredited dosimetry laboratory. 
Table 5

Comparison of the performed tests of various TLD reader models

\begin{tabular}{|c|c|c|c|c|c|c|}
\hline \multirow[t]{2}{*}{ Test } & Model: & $\begin{array}{l}\text { Harshaw } \\
6600+{ }^{(a)}\end{array}$ & $\begin{array}{l}\text { Harshaw } \\
\mathbf{8 8 0 0 +}{ }^{(b)}\end{array}$ & $\begin{array}{l}\text { Harshaw } \\
\text { 6600 }^{(c)}\end{array}$ & \begin{tabular}{|l|} 
RSD \\
7200 $^{(d)}$ \\
\end{tabular} & $\begin{array}{l}\text { RSD } \\
\text { 7103+ (e) }\end{array}$ \\
\hline & Standard & IEC 61066 & IEC 62387 & IEC 62387 & IEC 62387 & IEC 62387 \\
\hline $\begin{array}{l}\text { Non-linearity of } \\
\text { Response }\end{array}$ & & & $\checkmark$ & $\checkmark$ & $\checkmark$ & $\checkmark$ \\
\hline Reusability & $\checkmark$ & & $\checkmark$ & Not reported & $\checkmark$ & $\checkmark$ \\
\hline Stability & $\checkmark$ & & $\checkmark$ & $\checkmark$ & $\checkmark$ & $\checkmark$ \\
\hline Light exposure & $\checkmark$ & & $\checkmark$ & Not reported & $\checkmark$ & $\checkmark$ \\
\hline Temperature & $\checkmark$ & & $\checkmark$ & $\checkmark$ & $\checkmark$ & $\checkmark$ \\
\hline Power supply & $\checkmark$ & & $\checkmark$ & Not reported & $\checkmark$ & $\checkmark$ \\
\hline $\begin{array}{l}\text { Total uncertainty } \\
\text { for reader tests }\end{array}$ & & reported & $\checkmark$ & Not reported & $\checkmark$ & $\checkmark$ \\
\hline
\end{tabular}

(a) Velbeck et al.,(b) Luo et al.,(c) Rizk, and Vanhavere (d) Malek Mohammadi \& H-Pooya, (e) Current work

\section{ACKNOWLEDGEMENT}

The authors wish to thank the Secondary Standard Dosimetry Laboratory staff of Iran as well as Mrs. F. Vahhabi Asil and Mr. S. J. Bizeh for their assistance in this research work.

\section{REFERENCES}

1. 1. IAEA, International Atomic Energy Agency, Occupational Radiation Protection, IAEA Safety Standard, No: GSG-7 (2018).

2. IEC, International Electrotechnical Commission, Thermoluminescence dosimetry systems for personal and environmental monitoring, IEC 61066 Ed. 2 (2006).

3. IEC, International Electrotechnical Commission, Radiation protection instrumentation-passive integrating dosimetry systems for personal and environmental monitoring of photon and beta radiation, IEC 62387 (2012).

4. J. G.Alves, R. Montezuma, O. Margo, L.Santos, Study on quality control parameters of a TLD system for individual monitoring, Radiat. Prot. Dosim. 111, 21-25 (2004).

5. K. J. Velbeck, L. Z. Luo, K. L. Streetz, Type testing the model 6600 plus automatic TLD reader, Radiat. Prot. Dosim. 120, 303-306 (2006).

6. K. J. Velbeck, L. Z. Luo, K. L. Streetz, Type testing the model 6600 plus automatic TLD reader, Radiat. Prot. Dosim. 120, 303-306 (2006).

7. M. Weinstein, Y. Shemesh, A. Abraham, U. German, Use of statistical checks as maintenance tools for TLD readers, Radiat. Prot. Dosim. 125, 109-112 (2007).

8. L. Z. Luo, K. J.Velbeckand, J. E. Rotunda, Experience of type testing Harshaw advanced TLD system to new IEC-61066 standard, Radiat. Meas. 43,594-598 (2008).

9. C.Rizk and F. Vanhavere, A study on the uncertainty for the routine dosimetry service at the Lebanese atomic energy commission using Harshaw 8814 dosemeters. Radiat. Prot. Dosim. 170, 168-172 (2016).

10. M. Malek Mohammadi and S. M. Hosseini Pooya, Type testing of model 7200 automatic TLD reader, Radiat. Prot. Dosim. 174 , 63-68 (2017).

11. J. Brunzendorf and R. Behrens, How to type test the coefficient of variation of an indication, Radiat. Prot. Dosim. 123, 21-31(2007).

How to cite this article

S. M. Hosseini Pooya, P. Rezaeian, E. Edalatkhah, Study on type-testing of a manual TLD-reader for dosimetry programs, Journal of Nuclear Science and Applications 2 (1): 61-67 (2022), DOI: 10.24200/jon.2022.1013 